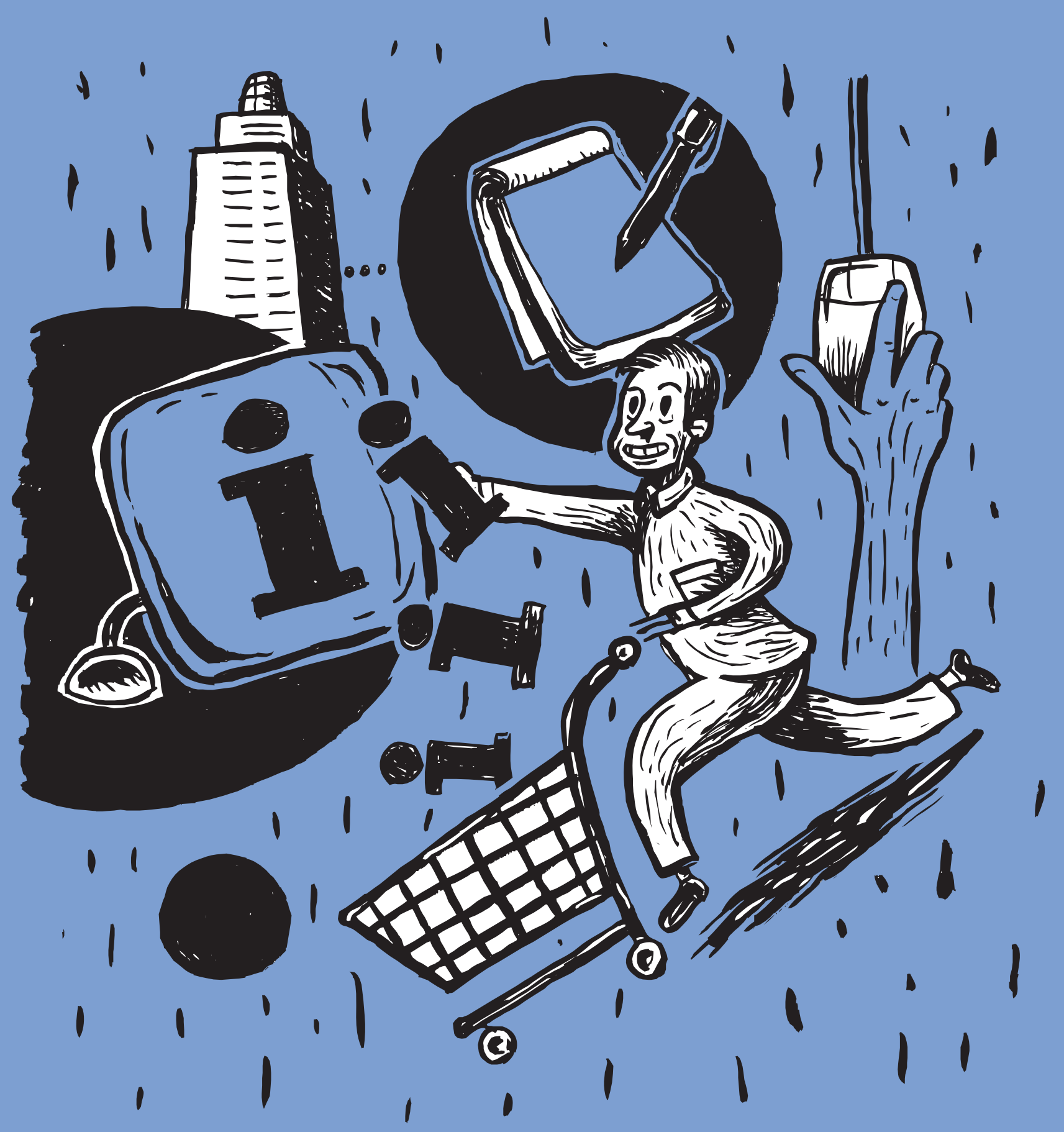




\section{Relaciones Públicas y Tecnología de la Comunicación. Analisys de los sitios de prensa virtuales}

\section{Antonio Castillo Esparcia}

- Doctor por la Universidad Autónoma de Barcelona

- Profesor de la Facultad de Comunicación de la Universidad de Málaga donde imparte las asignaturas Teoría y Técnica de las Relaciones Públicas y Sistemas y Procesos de las Relaciones Públicas

- Coordinador del Programa de Doctorado en Comunicación Organizacional.

- Director del grupo de investigación Las Relaciones Públicas en la Pequeña y Mediana Empresa.

- Coordinador Erasmus de la Facultad de Ciencias de la Comunicación de la Universidad de Málaga.

- Entre otras publicaciones, autor de Los grupos de presión ante la sociedad de la comunicación (2001); Comunicación Organizacional (2005), Industria audiovisual y publicitaria en Andalucía - Estudios sobre un sector estratégico (1998)

- acastilloe@uma.es

\section{Ana Almansa Martínez}

- Doctora por la Universidad de Málaga

- Profesora de la Facultad de Comunicación de la Universidad de Málaga donde imparte las asignaturas Relaciones Públicas Especializadas, Gabinetes de Comunicación y Comunicación Política

- Coordinadora del Doctorado Interuniversitario Nuevas tecnologías en Comunicación

- Entre otras, autora de Los Gabinetes de Comunicación: funciones y disfunciones

- anaalmansa@uma.es 
Resumo

As salas de imprensa virtuais transformaram-se em um dos principais instrumentos de relacionamento entre organizações e meios de comunicação. Diante das novas tecnologias, o trabalho dos relações-públicas melhora em rapidez, interação e ações dirigidas para públicos específicos. Este estudo analisa as salas de imprensa das dez empresas espanholas com maior faturamento para entender como se estrutura sua comunicação com os jornalistas.

PALAVRAS-CHAVE: SALAS DE IMPRENSA VIRTUAIS • RELAÇÕES PÚBLICAS • COMUNICAÇÃO

\section{Abstract}

The virtual press rooms have become one of the main relationship tools between organizations and mass media. By means of technologies, the work of the public relations improve in speed, interaction and actions directed to specific publics. This study analyses the press rooms of the ten companies with more revenue in Spain to see how the communication is structured with the journalists.

KEY WORDS: VIRTUAL PRESS ROOMS - PUBLIC RELATIONS • COMMUNICATION

\section{Resumen}

Las salas de prensa virtuales se han convertido en uno de los principales instrumentos de relación entre organizaciones y medios de comunicación. Mediante las tecnologías, el trabajo de los relaciones-públicas mejora en rapidez, interacción y acciones dirigidas a públicos específicos. Este estudio analiza las salas de prensa de las diez empresas con mayor facturación en España para ver cómo se estructura la comunicación con los periodistas.

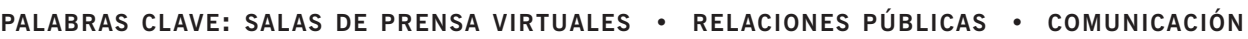


as Relaciones Públicas son una disciplina que desarrolla su labor en las interacciones entre organizaciones y públicos para acomodar las estrategias, finalidades y objetivos entre ambos. La aplicación de las tecnologías de la comunicación en las Relaciones Públicas va a ayudar a que las actividades se realicen de manera más segmentada y las capacidades comunicativas mejoren en eficacia y eficiencia debido a una especialización de las herramientas dirigidas a sus públicos. Uno de los elementos que más van a modificar esa relación son las tecnologías debido a que aportan rapidez, comunicación e interrelación ya que es posible elaborar mensajes específicas y canalizarlas mediante actividades concretas. Todo ello va a suponer una mejora considerable de uno de los aspectos más débiles como son las evaluaciones y confiabilidad de las estrategias comunicativas. Almansa (2005) señala que las tecnologías han modificado las rutinas productivas tradicionales y crean nuevas formas de trabajar (la intranet, por ejemplo).

Esa mejora se concreta en diversas ventajas para las Relaciones Públicas como es una mejor segmentación de los diferentes públicos que posee la organización, ya que permite una relación más personalizada y un mayor control del resultado. Esa relación implica interactuar permanentemente con los públicos, teniendo la posibilidad de resolver situaciones en tiempo real.

La irrupción de tecnologías ha favorecido los flujos de comunicación interpersonales e ínter organizacionales modificando estrategias, objetivos y herramientas. Las sociedades complejas y la expansión de Internet han supuesto una creciente capacidad de las Relaciones Públicas de expandir su actividad, por un lado, y de especializar las estrategias segmentando públicos, por otro lado. Gibson (2000) señala la capacidad de las webs corporativas para mantener relaciones interactivas con los públicos.

Sin embargo, existen aportaciones que inciden en la necesidad de que las tecnologías no eliminen el contacto humano entre personal de las organizaciones y públicos. Así desde esa perspectiva psicológica, Marken (1995) incide en la frialdad que supone remitir un correo y en la necesidad de que las relaciones con los periodistas se basen en el contacto personal. Cabe decir que esa situación y visión se ha ido suprimiendo progresivamente y las tecnologías no están sustituyendo el contacto humano.

En este sentido, las relaciones con los medios de comunicación también se han visto afectadas por esos nuevos avatares y surgen modalidades de interacción entre organizaciones y medios. Una de estas mutaciones han sido las denominadas Salas de Prensa 
Virtuales definidas como espacios comunicativos en red que contienen las herramientas y las actividades dirigidas a los medios de comunicación por parte de las organizaciones. Los estudios sobre el papel que juegan las tecnologías comienzan a ser numerosos y así Duke (2001) señala que el correo electrónico se ha convertido en una herramienta básica en las Relaciones Públicas con los medios.

Todo proceso de inserción de nuevos modelos y estructuras organizativas - como es el caso de las tecnologías en las Relaciones Públicas - conllevan la necesidad de acomodación a lo que son las características de los públicos de la institución. De esta manera, es innegable que las Salas de Prensa Virtuales suponen una creciente interacción entre periodistas y organizaciones y la posibilidad de generar flujos comunicativos on line. Sin embargo, el uso de estos soportes no debe alejarse de los requerimientos necesarios a la ilación entre organizaciones y medios y ésta debe basarse en la seriedad, veracidad e interacción, como elementos preexistentes y de permanencia inexcusable. De igual manera, con la creación de esos soportes se pueden generar nuevos procesos comunicativos que van dirigidos a los medios de comunicación, pero que son extensibles a cualquiera persona o institución interesada en disponer de información sobre nuestra organización. Eso supone una mejora de las relaciones con los públicos (Relaciones Públicas) y una cierta superación del canal periodístico para suministrar información a los stakeholders. Pero para poder ser eficaces es necesario actuar con criterios profesionales que permitan una rigurosidad entre datos e información. Esos criterios profesionales circulan en los carriles de la eficacia y eficiencia organizativas. Para poder realizar este cometido es adecuado exponer el modelo RACE de Marston puesto que ayuda a observar los pasos que deben darse en la implantación de una intranet. Este modelo postula la necesidad de que la evaluación sea elemento que anteceda y continúe con toda acción. En este sentido, Marston señala que la investigación (Research), debe ser anterior a la planificación ( $\underline{\text { Action }) ~ y, ~ q u e ~ p o s t e r i o r m e n t e, ~ s e ~ h a g a ~}$

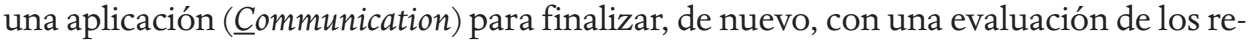
sultados (Evaluation). Las Salas de Prensa on line suponen la obligación de planificar convenientemente las estrategias de comunicación para que todo suponga una coherencia entre lo afirmado y lo realizado. Ya no es suficiente organizar una rueda de prensa sino que será pertinente realizar la grabación en audio y vídeo, deberemos realizar un seguimiento de nuestras apariciones mediáticas.

Cuando ya se ha decidido la creación de este elemento tecnológico estamos en disposición de conocer las mejoras y ventajas comunicativas que nos va a aportar a nuestra organización:

- Acceso simplificado a la información puesto que si la estructura de la intranet es lógica y adecuada la búsqueda es rápida y simple entre medios y organización. Además coadyuva a que los medios puedan solicitar datos e informaciones;

- Incremento y mejora de los flujos de comunicación por lo que será necesario establecer motores de búsqueda eficaces y potentes; 
- Mayor eficacia organizativa para los medios al disponer de las informaciones y datos con una gran rapidez;

- Incremento de la interactividad entre organización y empleados al disponer de respuestas inmediatas;

- Posibilidad de que los medios puedan disponer de información actualizada y permanente.

La aplicación de las tecnologías ha supuesto una mejora en la actividad de las Relaciones Públicas. La principal utilización son las páginas web que permiten dar a conocer a la organización a públicos que pueden estar en sitios muy lejanos (cuadro 1).

\section{Cuadro 1. Principales ventajas de internet ${ }^{1}$}

\begin{tabular}{|l|c|}
\hline Tipo de ventaja & $\%$ \\
\hline Dar a conocer a la empresa & 37 \\
\hline Mejorar la imagen & 33 \\
\hline Captar clientes & 24 \\
\hline Capacidad para captar comunicación & 20 \\
\hline Personalización de la comunicación & 10 \\
\hline Identificar nuevos clientes y mercados & 8 \\
\hline Crear relaciones personalizadas & 8 \\
\hline Fidelizar clientes & 8 \\
\hline Refuerza el posicionamiento & 6 \\
\hline Mayor retorno de la inversión realizada & 6 \\
\hline Comercio electrónico/vender & 4 \\
\hline NS/NC & 20 \\
\hline 1 & Estudio de Marketing y Publicidad en Internet en España, realizado por la Asociación \\
\hline
\end{tabular}

Desde esta perspectiva, es pertinente definir las principales características de una página web:

1 - Se trata de un medio especial porque demanda una reformulación específica de lo que es la organización y requiere un tratamiento creativo diferente del convencional y un mayor esfuerzo para poder combinar lo atractivo con lo práctico.

2 - Es un instrumento cuya característica más significativa es la interactividad, ya que es el visitante el que decide el itinerario que va a realizar, aunque siempre limitado a las posibilidades que le permita la configuración técnica y de contenido. A su vez su participación puede ser pasiva - limitándose a navegar por el contenido - o activa - Participando del chat que exista, dando su opinión por correo electrónico etc.

3 - Es multimedia en la que se integran los diferentes lenguajes, ya sean visuales, icó- 
nicos, audio, imágenes en movimiento. Todo ello le confiere una gran potencialidad en su capacidad de generar representaciones sobre la organización.

4 - El visitante suele ser una persona que está predispuesta, ya que es una búsqueda activa y eso implica una mayor efectividad en la comunicación, siempre y cuando se cumplan las expectativas generadas. Esta es una cuestión muy importante debido a que la página es la imagen que se ofrece de la organización a la colectividad y si esa imagen es negativa eso es peor que no tener ninguna imagen.

5 - No hay limitación de tiempo en su acceso, dejando que sea el propio usuario quien establezca el periodo de acceso y el tiempo de permanencia, configurando una gran libertad.

6 - Su contenido varía y se actualiza constantemente dependiente de las características y necesidades de cada página. El trabajo de realización de un espacio web no termina con su creación.

7 - No hay una especial limitación de espacio, teniendo la posibilidad de añadir de cualquier tipo de contenido independientemente de su espacio.

8 - Puede accederse desde cualquier ubicación geográfica por lo que es una herramienta esencial para aquellas organizaciones que actúan internacionalmente.

9 - Una permanente actualización del contenido en el que se incluyan cualquier nueva temática o la modificación de las existentes. Además, todo ello casi sin ningún coste adicional.

10- Permite una mayor segmentación de los públicos, aspecto que es esencial en las Relaciones Públicas al disponer de canales de comunicación que permiten interactuar con los diferentes públicos y las estrategias más adecuadas y pertinentes a ellos.

11- La rapidez en la comunicación implica una mejora de las prácticas de Relaciones Públicas al acometer una solución lo más rápida posible.

Según un estudio internacional presentado por Global Financial Communications Network, realizado entre 75 compañías de 10 países, las empresas consideran que las Relaciones Públicas son una herramienta importante para mejorar la credibilidad de la compañías que operan en la Internet, y de hecho, un 57\% de las empresas entrevistadas, creen que las Relaciones Públicas son aún más importantes para las punto.com que para las empresas tradicionales.

Sin embargo, la utilización de tecnologías de la comunicación no debe ser una decisión que se tome sin tener presente las características de la organización, la voluntad de realizarlo y, lo más importante, la exigencia de hacerlo desde postulados profesionales y serios. No hay que potenciar el uso de las tecnologías porque socialmente sea lo correcto, sino porque sea la consecuencia de una decisión meditada. Ello conlleva la necesidad de que si se decide realizar una Sala de Prensa on line, se implemente desde postulados profesionales y dirigida a los medios y no tanto a la necesidad social de hacer algo que esté de moda.

Las ventajas para las organizaciones son indudables, debido a que aportan inmedia- 
tez en la respuesta, permite la interactividad entre los usuarios y posibilita que puedan circular todo tipo de formatos de información en un mismo entorno. Kent y Taylor (2003, p.16) incluyen todo un listado de contenidos mínimos de la sala de prensa virtual como son:

- comunicados cronológicamente ordenados a la inversa;

- motor de búsqueda de palabras clave discursos (texto y sonido) por la fecha, el título, asunto;

- imagen gráfica informes anuales en HTML y archivos PDF;

- backgrounders y folletos con la información vital de la organización / producto;

- información de contacto actualizada (teléfono, fax, correo electrónico, dirección postal);

- establecer listas de distribución automatizadas, previa solicitud.

Asimismo, en la aplicación de las tecnologías de la comunicación en las Relaciones Públicas es necesario plantearse cuáles son las modificaciones que se producirán en los efectos de la comunicación. Para Jackson (1996) ésta es la cuestión esencial en la investigación ya que debemos conocer hasta que punto las tecnologías hacen que la Comunicación sea diferente en una organización. Sin embargo, en cualquier comunicación instrumentalizada por determinada tecnología no debe prevalecer el formato a través del cual se transmite sino que el contenido es el elemento sustancial, ya que es una comunicación elaborada y seleccionada por personas y que persiguen una finalidad pensada por y para los individuos. Ese planteamiento de la prevalencia tecnológica ha sido cuestionado por Nass y Mason (1990) que se centran en la vertiente personal de la Comunicación.

Las tecnologías de la comunicación desempeñan, asimismo, un papel remarcable en las estrategias externas que se realizan en toda organización. Esas herramientas coadyuvan a que la comunicación que realicemos llegue más rápidamente y de mejor manera a nuestros interlocutores. Empero, toda organización que sea opaca y poco creíble verá como esas ventajas se tornan en inconvenientes debido a que la interactividad que se produce actúa como espejo amplificador de esas carencias. De ahí que si eran necesarias la credibilidad y la apertura en la utilización de las herramientas más clásicas, en la nueva etapa de una profusa aplicación de tecnologías devienen en algo inexcusable. Eso posibilita que se incremente la distancia entre organizaciones que gestionan comunicativamente de manera adecuada su estrategia y aquellas que todavía se obcecan en ocultarse ante unos problemas que modifican la percepción de los distintos públicos - internos y externos - de la organización.

Gran parte de los estudios sobre la significación de la comunicación en línea se ha centrado en las aportaciones específicas a las estrategias de la Comunicación. Así las resoluciones de crisis, caracterizadas por la rapidez en la respuesta y la necesaria interacción con los públicos, han recibido múltiples estudios que analizan las mejoras que 
aporta la comunicación en línea. En este sentido, Perry, Taylor y Doerfel (2003) ya señalan que la resolución de situaciones de crisis exigen el uso de las tecnologías debido a su inmediatez. De igual manera, Taylor y Perry (2005) han incidido en las aportaciones de las tecnologías en el trabajo de las Relaciones Públicas.

\section{Investigación}

Uno de los elementos que se han introducido como valor añadido a las Relaciones Públicas es la segmentación de los públicos de las organizaciones y la concreción de herramientas y actividades específicamente dirigidas a esas audiencias. Hasta hace pocos años, los profesionales de las Relaciones Públicas nos encontrábamos con las dificultades de unas herramientas genéricas y que dirigían a grandes bloques de públicos. Eso dificultaba las estrategias e impedía especializar las actividades que se planificaban para conseguir los objetivos organizativos, sobretodo porque se debía recurrir a intermediaciones desde otras instancias para alcanzar a los públicos. Así, un problema añadido era cómo acceder a esas instancias especializadas. Una de las usuales era el acceso a los medios de comunicación para conseguir que nuestros mensajes llegaran al mayor número de personas y esas relaciones incidían sobre el qué, cómo, de qué manera y cuándo aparecían nuestras informaciones.

Las modificaciones en las relaciones con los medios se han ido acomodando a las características propias de los medios como una posición estratégica de adecuarse a las rutinas redaccionales y de producción mediáticas. Así, se concretaban en una serie de iniciativas como:

1 - Redacción propia de los textos de las organizaciones (comunicados, notas de prensa, artículos, entrevistas, dossier) con los criterios redaccionales de los medios y de los contenidos estructurales de las noticias e informaciones. Eso hacía que los periodistas no tuvieran que adecuar los textos a las características de su medio (prensa, radio y televisión) y al no cambiar se facilitaba que no se tuvieran que re-redactar por parte del periodista y la consiguiente pérdida de datos;

2 - Mimetización de las estructuras narrativas propias de cada medio como son la pirámide de interés decreciente en la prensa escrita, la redundancia en la radio y la doble codificación en los medios audiovisuales;

3 - Recurso al correo electrónico como modo de transmisión con las consiguientes ventajas que ello aporta:

- posibilidad de remitir con la misma transmisión a diferentes medios gracias a las listas de distribución;

- insertar en un mismo archivo datos escritos, sonoros y audiovisuales, con lo que las radios y las televisiones disponían de manera inmediata de una materia prima que respetaba sus fuentes originales de documentos; 
Al remitir el texto en formato electrónico ya se eliminaba el paso intermedio de volver a escribir el texto por parte del periodista puesto que con el correo electrónico el texto ya estaba en el ordenador.

Con esta perspectiva la iniciativa provenía, generalmente, de las organizaciones en el momento de proponer temas de publicación para los medios y eso obligaba a respetar tiempos propios de la labor periodística. Sin embargo, la aparición de espacios en los que se inserta los documentos informativos de las organizaciones ha ampliado esos tiempos a las veinticuatro horas y permite que los medios puedan acceder a unos datos de manera on line y sin la intermediación anterior que podía llevar a retrasos en la respuesta. A su vez, ofrece informaciones diacrónicas a los periodistas permitiendo que se puedan concretar espacios periodísticos de tratamiento informativo de las organizaciones al margen de la actualidad más novedosas. Esos espacios se han denominado de diferentes maneras pero usualmente se les conoce como Press Room, Salas de Prensa Virtuales u On line.

Así esta investigación persigue analizar cómo se estructuran esas Salas y los contenidos que en ellas se ofrecen para poder estudiar si esos espacios han modificado las relaciones, los contenidos y las herramientas entre organizaciones y medios de comunicación. Para poder seleccionar una muestra significativa que permitiese analizar el qué, cómo, de qué manera, por qué del contenido de las Salas de Prensa se eligió una muestra de los diez grupos empresariales de mayor venta en España, ya que las empresas más grandes son las que pueden dedicar más recursos económicos, materiales y personales a esos espacios. El total de empresas seleccionadas facturan un máximo de cuatro mil millones y medio de euros (Telefónica) y un mínimo de ochocientos millones de euros (Carrefour España). El total de ventas de las diez empresas es de casi ciento setenta mil millones de euros (169.921 millones de euros).

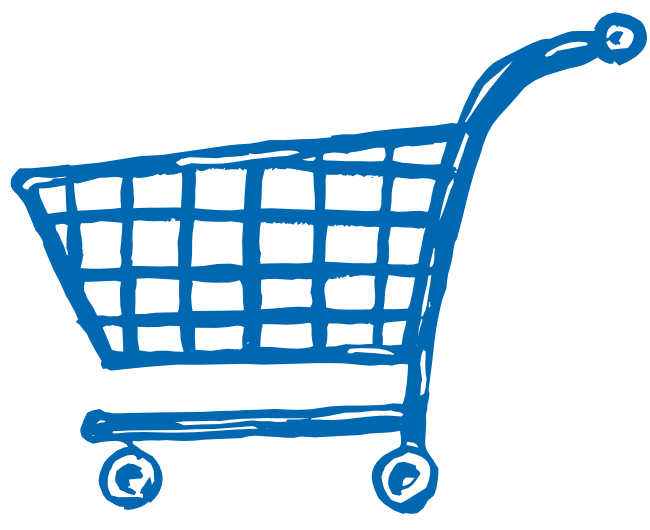


RELACIONES PÚBLICAS Y TECNOLOGÍA DE LA COMUNICACIÓN. ANALISYS DE LOS SITIOS DE PRENSA VIRTUALES • ANTONIO CASTILLO ESPARCIA E ANA ALMANSA MARTÍNEZ

Cuadro 2. Relación de empresas analizadas

\begin{tabular}{|l|l|c|}
\hline \multicolumn{1}{|c|}{ GRUPO } & \multicolumn{1}{c|}{ URL } & INGRESOS (miles de euros) \\
\hline 1 - Repsol YPF & http://www.repsolypf.com & 36.069 \\
\hline 2 - Telefónica & http://www.telefonica.es/ & $28399,84+10.070$ \\
\hline & & $\begin{array}{c}+6.377 \text { (telefonica } \\
\text { moviles + telefonica } \\
\text { internacional) }\end{array}$ \\
\hline 3 - Endesa & http://www.endesa.es & 16.239 \\
\hline 4 - El Corte Inglés & http://www.elcorteingles.es & 14.056 \\
\hline 5 - Compañía Española de Petróleo & http://www.cepsa.com & 13.199 \\
\hline 6 - Mondragón Corp. Corporativa & http://www.mondragon.mcc.es & 9.655 \\
\hline 7 - Iberdrola & http://www.iberdrola.com & 9.488 \\
\hline 8 - Altadis & http://www.altadis.com & 9.473 \\
\hline 9 - ACS & http://www.grupoacs.com & 8.825 \\
\hline 10 - Carrefour & http://www.carrefour.es & 8.071 \\
\hline
\end{tabular}

Se ha utilizado una muestra de los principales grupos empresariales en España por ingresos en el año 2003 según el Fomento de la Producción, 2004 (www.fomenweb.com). Mediante la técnica del análisis de contenido se han analizado las Salas de Prensa Virtuales de los diez primeros grupos de empresas españolas en el año 2003, según aparece en el listado de empresas y los ingresos. La plantilla de análisis estudiaba aspectos estructurales, de contenido y de usabilidad. Los análisis se efectuaron en el mes de mayo de 2005. La estructura metodológica de la plantilla de análisis se basaba en preguntas dicomóticas sobre presencia / ausencia de las herramientas dirigidas a los medios (comunicados, ruedas de prensa, dossier de prensa, biografía, soportes fotográficos y documentos audiovisuales).

\section{Resultados}

Las denominadas Salas de Prensa Virtuales u On line van dirigidas a los profesionales de la comunicación como una manera de mejorar las relaciones con los medios. Consecuentemente van dirigidas de manera específica a los periodistas, pero no todas tienen un acceso abierto a sus contenidos. Los argumentos para restringir el acceso a esas salas son el hecho de que se puede ofrecer información más específica, con mayor profundidad y con aspectos más profesionales. De ahí que algunas empresas demanden la necesidad de registrarse y limitar su acceso sólo a los profesionales. En el caso de nuestro análisis nos encontramos con que el $90 \%$ de las empresas no restringen el acceso, mientras que la empresa Repsol-Ypf señala que: "éste es un espacio dedicado a los profesionales de la comunicación”, por lo que existe un registro previo. 


\section{Gráfico 1. Tipo de acceso}

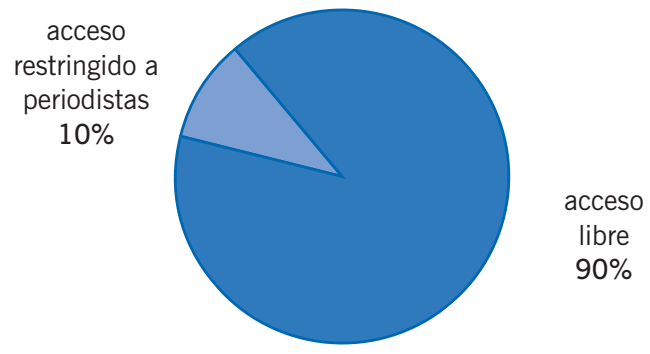

Este aspecto es uno de los elementos significativos respecto del grado de profundización de los datos que se pueden insertar en la sala de prensa.

Igualmente significativo es el nombre que recibe ese espacio en el que se ubican los contenidos referidos a los medios de comunicación. Dentro de los organigramas usuales de las empresas encontramos numerosas denominaciones (Prensa, Relaciones Informativas, Relaciones Externas, Director de Comunicación, Director de Relaciones Públicas etc.). Sin embargo, en los casos de los sitios web las denominaciones se limitan mucho.

\section{Gráfico 2. Nombre de la sala}

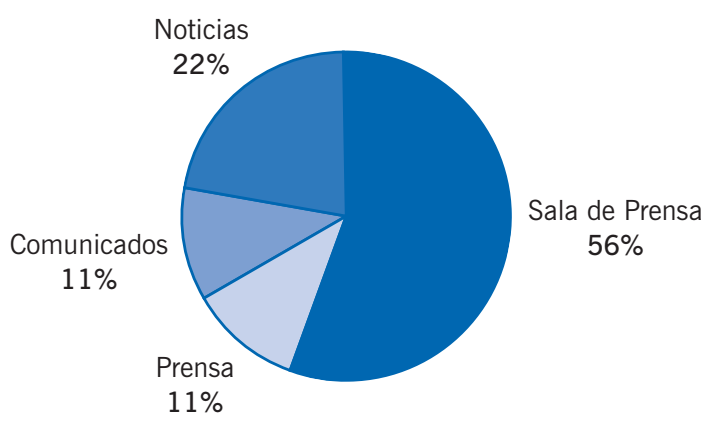

Así, la denominación más recurrente es la Sala de Prensa (56\%) como sitio que recoge todos los aspectos relacionados con los medios. Seguidamente nos encontramos 
con Noticias con un $22 \%$ y que intenta reflejar lo que realmente son estos espacios ya que básicamente se limitan a recoger los comunicados emitidos por las empresas (algo sobre lo que profundizaremos más adelante). Finalmente, aparecen Comunicados y Prensa con un $11 \%$, que restringe todavía más el significado pero que resulta más adecuado respecto al contenido que pueden encontrar las personas que acceden a él.

Señalábamos que estos espacios contienen una serie de actividades y herramientas dirigidas a los medios de comunicación y son un espacio de consulta para los periodistas. Sin embargo, de total de acciones que podemos entablar con los profesionales de la información, podemos observar que las Salas de Prensa on line son meros receptáculos o bases de datos sin existir, apenas, capacidad de interacción y de interrelación entre periodistas y empresa. Si bien es cierto que en el $88 \%$ se ofrecen la posibilidad de contactar con los responsables de Comunicación (vía teléfono, fax, correo electrónico) no se puede afirmar que se produzca comunicación sino que sólo existe una unidireccionalidad (los periodistas acceden a los documentos que les suministra la organización). Y ese planteamiento estratégico se traslada al conjunto de la Sala de Prensa puesto que sus contenidos suelen ser bastantes estáticos y unidireccionales.

Respecto de las múltiples herramientas relacionales existe una presencia preponderante de los comunicados de prensa respecto de otras actividades. Así todas las empresas analizadas ofrecen los comunicados realizados por la organización. La búsqueda de esos comunicados se puede realizar por criterio cronológico (100\%) o por criterio temático, aunque este último sólo lo permite el 33\%. Respecto del criterio cronológico, la antigüedad de los comunicados es apreciable y encontramos comunicados en algunas empresas que datan de 1997 y en todas existe una antigüedad mínima (a fecha de mayo de 2005) del año 2001, es decir, encontramos los comunicados de los últimos cuatro años.

Otro aspecto a considerar es la inclusión de los comunicados según el formato original. Así, el 66\% sólo contienen el texto del comunicado y no aparecen los comunicados tal como se han redactado y enviado (con formato organizativo).

\section{Gráfico 3. Formato del texto}

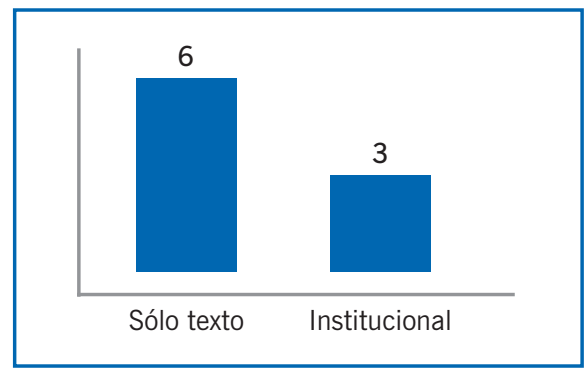


Con relación al resto de las actividades relacionales con los medios de comunicación, las fotografías poseen una presencia remarcable y su contenido casi es unánime. Las fotografias se refieren a directivos de la empresa o a otros ámbitos (sedes, proyectos, sucursales etc.).

\section{Gráfico 4. Actividades dirigidas a los medios de comunicación}

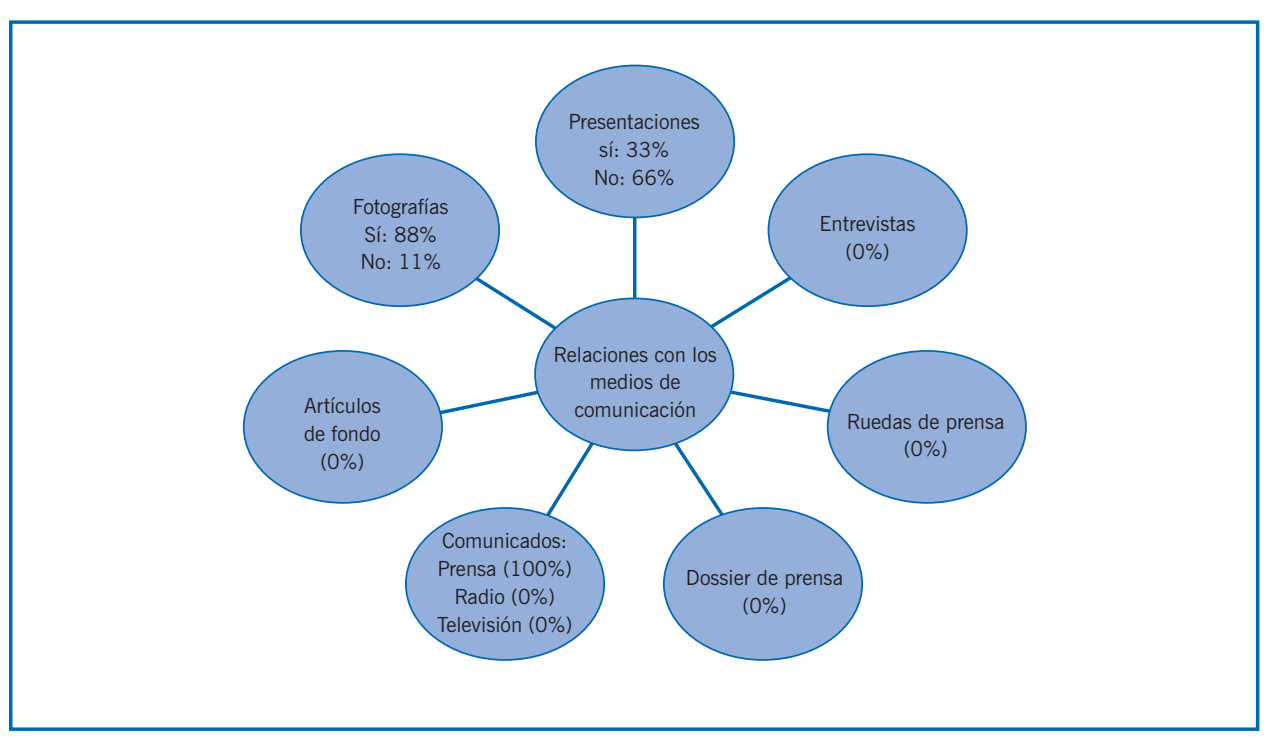

No se puede afirmar que las Salas de Prensa on line sean espacios en los que se ofrece información a los periodistas ya que del conjunto de acciones dirigidas a los medios sólo concurren los comunicados de prensa, las fotografías y las presentaciones de actos. Con el inconveniente de que las fotografias contienen en pocas ocasiones una pequeña biografía de los implicados. A su vez en el caso de las presentaciones, éstas se refieren a las realizadas ante los medios comunicativos como a otros tipos de auditorios (potenciales inversionistas, resultados ante accionistas). Finalmente, en el ámbito de los comunicados se han distinguido aquellos que se habían realizado y estructurado específicamente para cada tipo de medio (prensa, radio y televisión). Sólo hemos encontrado comunicados redactados para la prensa y no existen comunicados para radio y televisión y su consiguiente estructura narrativa. Eso implica una total inexistencia en el aprovecho de las ventajas que ofrecen las nuevas tecnologías:

- se pueden remitir al mismo tiempo un comunicado con documentos sonoros para las radios, lo que redundará en su facilidad para ser introducido en los informativos;

- respecto de las imágenes para las televisiones existe el problema de la calidad pe- 
ro no se realizan esfuerzos en esta materia. Cabe resaltar que los propios medios son más partidarios de recibir las imágenes sin editar puesto que lo contrario supone una limitación en la capacidad de seleccionar los periodistas.

Resaltar la nula presencia de los dossier de prensa ya que eso no supone ningún tipo de coste adicional a lo ya realizado puesto que los dossier han sido elaborados en un ordenador y trasladar esa información al web site es meramente una decisión y no un trabajo adicional. En el caso de las tecnologías y su inserción en las salas de prensa no se entiende que poca potencialidad que se les supone debido a que depende más de un proceso estratégico de decisión (el querer hacer) y no tanto un problema de personal, de infraestructura o de presupuesto. Hay que tener presente que todos los documentos que se pueden insertar en las salas de prensa ya han sido elaborados para realizar las herramientas tradicionales:

1 - Los comunicados han sido redactados en un ordenador y están archivados en un documento. Consecuentemente se puede trasladar sin ningún problema.

2 - Las ruedas de prensa se ofrecen a los medios y se puede disponer de una cámara que grabe en un formato de DVD cuesta hoy en día 600 euros. Con esa grabación tendremos toda nuestra intervención que podríamos insertar en nuestra sala

3 - Las presentaciones realizadas antes diferentes públicos se suelen realizar mediante programas de presentación. Uno de los más extendidos es el formato PDF, pues cuando lo realizamos para la presentación, automáticamente es un archivo que también podemos introducir en la sala.

4 - Las fotografías también se guardan en formato digital e igualmente es sencillo trasladarlas. Si además nos referimos a una fototeca sobre nuestros directivos es sencillo adjuntar o adicionar un pequeño curriculum vitae de la personas lo que aporta valor añadido al periodista. Además en muchos sitios se pueden descargar fotografías a diferentes resoluciones.

5 - El dossier de prensa que realizamos para una rueda de prensa también se realiza en un ordenador. Es fácil trasladarlo a la Sala de Prensa on line.

6 - Entrevistas que se hayan realizado a nuestro personal en los medios sólo es necesario escanearlas e insertarlas. Asimismo, en algunas organizaciones se adelantan a los medios sobre aspectos muy actuales y los propios gabinetes realizan algunas preguntas a los directivos y las trasladan a la sala para que todos los periodistas las puedan consultar. Y eso no sólo escrito sino que también como archivo sonoro y / o visual

7 - Los artículos de fondo que parecen en medios y que se realizan ad hoc para nuestra sala sólo es cuestión de decidir insertarlos porque ya están en un formato de documento digital.

Como observamos todas las herramientas que se pueden insertar en una Sala de Prensa Virtual no suponen apenas esfuerzo y no implica el aumento del personal ni dedicación a una actividad específica. Es el resultado de una planificación sensata y profesional por lo que es económico y sencillo con unos resultados muy satisfactorios. 
Otros elementos que se pueden insertar tienen una presencia nula. Así, no encontramos elementos que interactúen con los periodistas y que pueden suponer un valor añadido a lo que supone este tipo de espacios como son las Salas de Prensa on line. En este sentido:

- Los recorridos virtuales que puedan complementar una información audiovisual no aparecen en ninguna de las empresas analizadas;

- Sólo existe un $11 \%$ de empresas que ofrecen la descarga de imágenes en movimiento ya sean de ruedas de prensa, de presentaciones o de cualquier otra temática;

- Los periodistas no pueden realizar entrevistas a directivos en tiempo real. Algo que sería de interés informativo y nos permitiría aparecen como noticia;

- No existen documentos sonoros de la organización sobre entrevistas o declaraciones.

\section{Gráfico 5. Presencia de elementos interactivos}

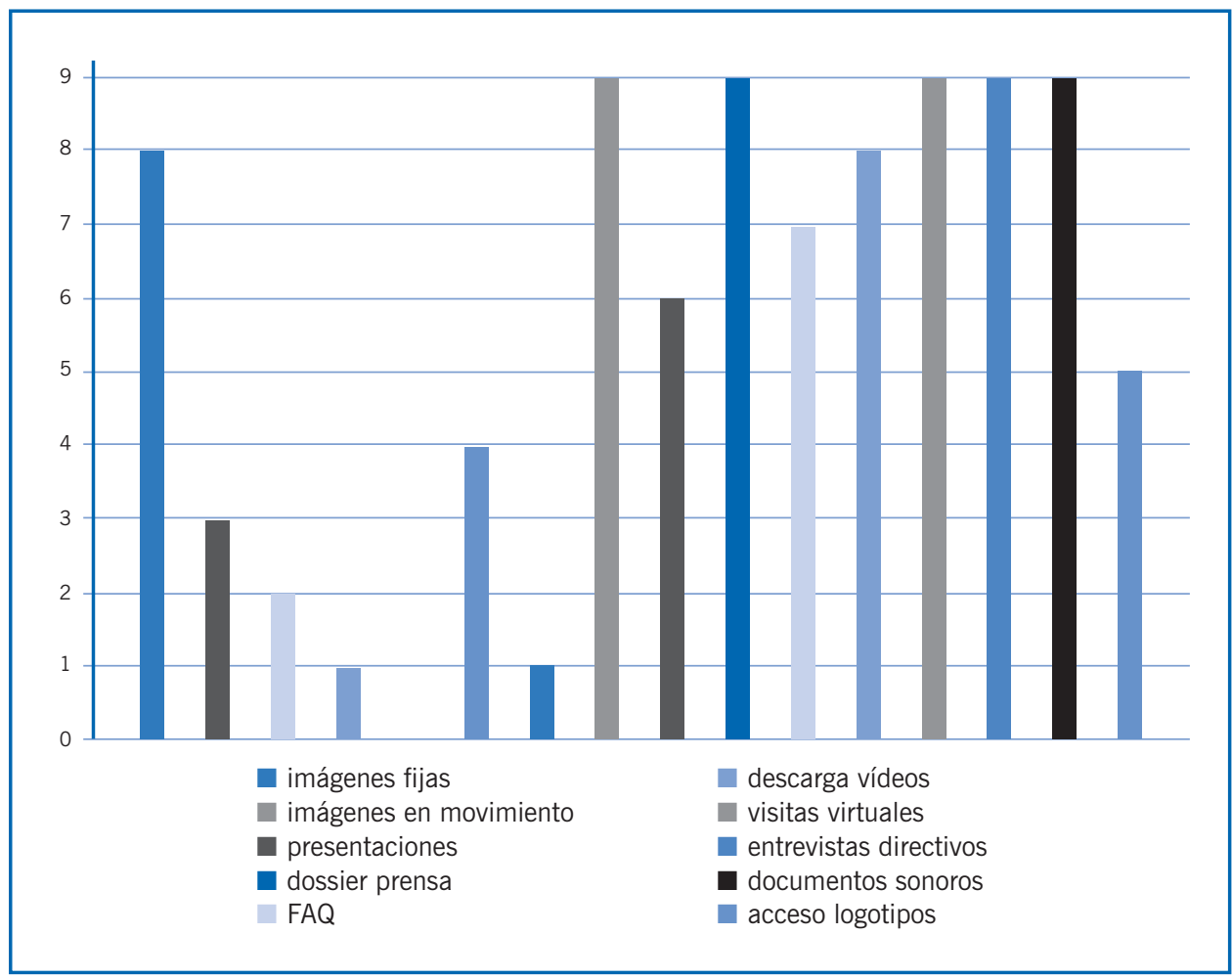

Así vemos que en estas salas impera más lo estático a lo dinámico, lo unidireccional a lo bidireccional y lo escrito a lo audiovisual. 
RELACIONES PÚBLICAS Y TECNOLOGÍA DE LA COMUNICACIÓN. ANALISYS DE LOS SITIOS DE PRENSA VIRTUALES • ANTONIO CASTILLO ESPARCIA E ANA ALMANSA MARTÍNEZ

\section{Conclusiones}

Tras analizar a los grupos empresariales más grandes de España es conveniente señalar que existe una escasa utilización de las tecnologías en las relaciones con los medios de comunicación. Las ventas que aportan esas tecnologías (interacción, rapidez, bidireccionalidad, especialización) no son utilizadas en las Salas de Prensa de esas empresas. Se observa que son meras traslaciones de elementos ya realizados sin que se aporten novedades aunque se modifique el espacio. Podríamos señalar que estas Salas están mimetizando lo que fue la traslación de los periódicos a Internet, esto es, una foto fija de lo que ya eran pero en un espacio totalmente diferente.

Las herramientas más utilizadas son los comunicados de prensa (100\%), la fotografias (88\%) y las presentaciones (33\%). Apenas encontramos vídeos corporativos (11\%) y acceso a logotipos (33\%). No aparecen visitas virtuales, entrevistas a directivos, dossier de prensa ni documentos sonoros y audiovisuales. Callison (2003) ha estudiado el contenido de las Salas de Prensa Virtuales y apuntaba como materiales más comunes los comunicados de prensa, biografias y fotografías, con una clara ausencia de elementos que contengan imágenes en movimiento y elementos sonoros.

Todo esto muestra unas Salas de Prensa que son estáticas, con escasa información, unidireccionales y nula utilización de las potencialidades de las tecnologías. Frente a unos medios de comunicación que recurren cada vez más a la información que nos muestra Internet, las empresas no dedican suficientes recursos materiales, personales ni estratégicos a potenciar sus Salas de Prensa.

Desde esta perspectiva las Salas de Prensa analizadas no se recurren a la potencialidad que aportan las tecnologías y la planificación en la gestión de estos soportes es escasa. Eso imposibilita conseguir una mejora en la interacción dialógica y la rapidez.

\section{Bibliografía}

ALMANSA, Ana. La comunicación organizacional en España: un camino a medio recorrer. En CASTILLO, A.: Comunicación Organizacional: teorías y estudios, Málaga: Ed. Clave Aynadamar, 2005, p. 11-29.

CALLISON, Coy. Media relations and the Internet: how Fortune 500 company web sites assist journalists in news gathering. Public Relations Review, Volume 29, Issue 1, 2003, p. 29-41.

DUKE, Shearlean. E-mail: Essential in media relations, but no replacement for face-to-face communications, in Public Relations Quarterly,Vol. 46, Iss. 4, 2001, p. 19-22

GIBSON, Dirk C. The cyber-revolution in product recall public relations en Public Relations Quarterly, Vol.45, Iss. 2, 2001, p. 24-26. 
RELACIONES PÚBLICAS Y TECNOLOGÍA DE LA COMUNICACIÓN. ANALISYS DE LOS SITIOS DE PRENSA VIRTUALES • ANTONIO CASTILLO ESPARCIA E ANA ALMANSA MARTÍNEZ

HOLTZ, Shel . Public Relations on the Internet. New York: AMACOM, 1999.

JACKSON, M. H. The meaning of "communication technology": the technology-context scheme. En BURLESON,

B. (Ed.). Communication Yearbook, Vol. 29, Thousand Oaks, CA: Sage Publications, 1996, p. 228-267.

KENT, Michael y TAYLOR, Maureen. Maximizing media relations: a web site checklist. En Public Relations Quarterly, Rhinebeck, Vol.48, Iss. 1, 2003, p. 14-18.

MARKEN, G. A. E-mail enhances contact, not content, en Public Relations Quarterly, Vol. 40, Iss. 2, 1995, p. 47-49.

MIDDLEBERG, D. Relaciones Públicas en un mundo interconectado. Pamplona: Deusto, 2001.

NASS, C. y MASON, L. On the study of technology and task: a variable-based approach. En FULK, J. y STEINFIELD, C. W. (Eds). Organizationd and communication technologies. Newbury Park: Sage, 1990, p. 4668.

PERRY, D. C., TAYLOR, M., \& DOERFEL, M. Internet based communication in crisis management. En Management Communication Quarterly, 17(2), 2003, p. 206-233.

TAYLOR, M. y PERRY D. C. Diffusion of traditional and new media tactics, communication. En Public Relations Review, n. 31, 2005, p. 209-217.

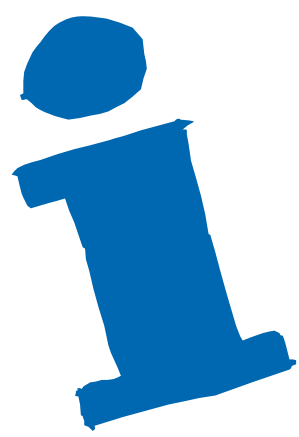

